\title{
Cytological evaluation of thyroid lesions and its correlation with histopathology in a teaching hospital
}

\author{
M. Kanyakumari1 ${ }^{1,}$, K. Pushpalatha ${ }^{2}$ \\ ${ }^{1}$ Associate Professor, ${ }^{2}$ Professor and HOD, Dept. of Pathology, Maheshwara Medical College, Patancheru, Telangana, India
}

*Corresponding Author: M. Kanyakumari

Email: kanya235@gmail.com

Received: $6^{\text {th }}$ March, 2018

Accepted: $26^{\text {th }}$ June, 2018

\begin{abstract}
Aim of the Study: To study the cytomorphological features in various thyroid lesions and to correlate the cytological features with histopathological study of surgically removed thyroid lesions.

Materials and Methods: Both retrospective and prospective study was carried out at Department of Pathology, Maheshwara Medical College and Hospital, over a period of two years. Patients from General Surgery, ENT, Paediatrics and from General Medicine OPD were taken for FNAC. Thyroid FNACs in 94 patients were done during this period and 69 cases underwent histopathological examination. The findings of FNAC and histopathology were compared.

Results: Patient age ranged from 9 to 75 years. Majority of the patients (28.7\%) were in the 21-30 years age group. The male to female ratio was 1:22.4. On cytology, Nodular goitre was the most common diagnosis (39.3\%). Follicular neoplasm was reported in 04 cases $(4.2 \%)$. On Histopathology, benign diagnosis (91.3\%) far outnumbered the malignant ones $(8.6 \%$ cases). FNAC showed overall diagnostic accuracy of $98.5 \%$ with specificity of $100 \%$, sensitivity of $85.7 \%$, Positive predictive value of $100 \%$, and Negative predictive value of $98.4 \%$.

Conclusion: FNAC technique showed good reliability in diagnosing thyroid lesions in our institute. It showed $100 \%$ specificity, high sensitivity and high accuracy. Though FNAC cannot replace the gold standard of histopathology, this technique has many advantages and helps in preoperative diagnosis of thyroid lesions which guides the further clinical management of patients with thyroid swellings.
\end{abstract}

Keywords: FNAC of thyroid, Cytology and Histopathology correlation, Nodular goitre.

\section{Introduction}

Thyroid fine-needle aspiration cytology (FNAC) was introduced in 1950 and became popular worldwide in $1980 .{ }^{1}$ Today, it is a well-established technique for preoperative diagnosis of thyroid pathologies. Thyroid lesions may cause sign and symptoms of hypothyroidism or hyperthyroidism and also have malignant potential. ${ }^{2}$

FNA has now replaced most other tests used for pre-operative diagnosis of thyroid lesions. Now-a-days, most clinicians rely solely on FNA for making a diagnosis of benign lesions. As a result the incidence of malignancy in thyroidectomy patients has increased from $10 \%$ to $30-50 \%$ in recent years. ${ }^{3}$

FNAC is a diagnostic tool in which cells are aspirated from a palpable swelling using syringe and fine needle. It is a simple, minimally traumatic, speedy, safe, cost-effective and an accurate technique being used worldwide. FNAC is being increasingly used for evaluation of thyroid swellings due to these advantages. ${ }^{4}$

Fine needle aspiration cytology (FNAC) is now being accepted as the most cost-effective, minimal invasive technique with very low incidence of complications in the diagnosis of most of the thyroid lesions with an added advantage of segregating the patients of solitary thyroid nodule (STN) into operative and non-operative groups. ${ }^{5,6}$
FNAC is considered to be the "gold standard" in the selection of patients for surgery. ${ }^{7}$

Still the histopathological examination of the thyroid gland is considered superior to FNAC in diagnosing the thyroid pathologies due to certain pitfalls in FNAC such as scanty sample, vascularity of thyroid swelling, variation in sampling technique and skill of the performing expert and as well as the experience of pathologist interpreting the aspirate. ${ }^{8}$

Hence, this study was undertaken to study the cytology of palpable thyroid lesions to minimize surgical intervention and also the need for the confirmation of the diagnosis by histopathological study for planning post-surgical management of malignant thyroid lesions.

\section{Aim of the Study}

To study the cytomorphological features in various thyroid lesions and to correlate the cytological features with histopathological study of surgically removed thyroid lesions.

\section{Materials and Methods}

Informed consent was taken from the patients. Both retrospective and prospective study was carried out in the department of Pathology, Maheshwara Medical College and Hospital, for a period of two years ie, from February 2016 to January 2018. One year was retrospective and one year was prospective. 
Patients referred from the departments of general surgery, ENT, paediatrics and from general medicine OPD who presented with neck swellings of thyroid origin, were taken for FNAC.

94 FNACs were done during this period.

\section{Inclusion Criteria:}

1. All age groups and both the genders

2. Only thyroid swellings

3. Ultrasound guided FNA material was also included Exclusion Criteria:

1. Inadequate samples

2. Patients undergoing repeat FNA during the study period were considered only once.

Out of 94 patients, histological confirmation was available in 69 cases.

Clinical data included age, gender, clinical features and thyroid function tests (TFT).

All FNA were done by the pathologist as an outpatient procedure. The procedure was explained to the patient, aspiration was done with the patient in supine or sitting position with extended neck, so as to make the thyroid swelling appear prominent. The material was obtained by using a $2.5 \mathrm{~cm}$ long, 23-25 gauge needle attached to a $5 \mathrm{cc}$ or $10 \mathrm{cc}$ disposable syringe. Ultrasound guided FNA was done in a few cases.

The material was collected, smears were made and immediately wet fixed for hematoxylin and eosin staining and papanicolaou staining. Air dried smears were stained with Giemsa stain.

Out of 94 cases, 69 cases came for histopathological examination. Some cases did not come for follow up and some cases were treated symptomatically.

The results of FNAC were compared with histopathology in 69 cases.

The tissue specimens were collected in $10 \%$ formalin in fresh state and were allowed to fix overnight.

Detailed gross examination was done and representative bits were given. Paraffin embedded H\&E stained sections were obtained and studied under light microscopy. Cytological diagnosis was correlated with histopathological diagnosis.

The diagnostic accuracy, sensitivity and specificity, positive predictive value (PPV) and negative predictive value (NPV) of FNAC in diagnosing thyroid malignancy were calculated.

\section{Results}

Table 1: Age distribution of cases in cytology

\begin{tabular}{|l|c|c|}
\hline \multicolumn{1}{|c|}{ Age } & No. of cases & Percentage \\
\hline $1-10$ & 01 & $1 \%$ \\
\hline $11-20$ & 17 & $18 \%$ \\
\hline $21-30$ & 27 & $28.7 \%$ \\
\hline $31-40$ & 19 & $20.2 \%$ \\
\hline $41-50$ & 16 & $17 \%$ \\
\hline $51-60$ & 07 & $7.4 \%$ \\
\hline $61-70$ & 06 & $6.3 \%$ \\
\hline $70-80$ & 01 & $1 \%$ \\
\hline Total & 94 & $100 \%$ \\
\hline
\end{tabular}

The patient age ranged from 9 years to 75 years.

Majority of the patients were in the age group of 21-30 years $27 / 94$ (28.7\%) followed by 31-40years $19 / 94(20.2 \%)$.

Gender Distribution: There were 95.7\% (90/94) female patients and $4.2 \%$ (04) male patients, the male to female ratio being 1:22.4.

Distribution of Cases based on Clinical Presentation: Solitary thyroid nodule (right lobe) was seen in $43(45.7 \%)$ cases and of left lobe was seen in 28 $(29.7 \%)$ cases. Multinodular goitre and diffuse thyroid swelling were seen in $12(12.7 \%)$ and in $11(11.7 \%)$ cases respectively.

Clinically, solitary thyroid nodule was the most common presentation and was seen in $71 / 94$ (75.4\%) cases.

Table 2: Distribution of cases based on cytology

\begin{tabular}{|l|c|c|}
\hline \multicolumn{1}{|c|}{$\begin{array}{c}\text { Cytological } \\
\text { diagnosis }\end{array}$} & $\begin{array}{c}\text { No. of } \\
\text { cases }\end{array}$ & $\begin{array}{c}\text { Percentage } \\
(\%)\end{array}$ \\
\hline Colloid cyst & 03 & $3.1 \%$ \\
\hline Colloid goitre & 11 & $11.7 \%$ \\
\hline Nodular goitre & 37 & $39.3 \%$ \\
\hline $\begin{array}{l}\text { Hashimoto's } \\
\text { thyroiditis }\end{array}$ & 26 & $27.6 \%$ \\
\hline $\begin{array}{l}\text { Lymphocytic } \\
\text { thyroiditis }\end{array}$ & 02 & $2.1 \%$ \\
\hline Subacute thyroiditis & 01 & $1.0 \%$ \\
\hline Thyroglossal cyst & 04 & $4.2 \%$ \\
\hline Follicular neoplasm & 04 & $4.2 \%$ \\
\hline $\begin{array}{l}\text { Suspicious of } \\
\text { Malignancy }\end{array}$ & 06 & $6.3 \%$ \\
\hline Total & 94 & $100 \%$ \\
\hline
\end{tabular}

In the present study, the non-neoplastic lesions were more common than neoplastic lesions. Among non- neoplastic lesions, Nodular goitre and Hashimoto's thyroiditis were common. Among neoplastic lesions, follicular neoplasm was reported in 04 cases $(4.2 \%)$ 
Table 3: Distribution of cases based on histopathology

\begin{tabular}{|l|c|c|}
\hline Histopathology diagnosis & No. of cases & Percentage (\%) \\
\hline Colloid cyst & 3 & $4.3 \%$ \\
\hline Thyroglossal cyst & 4 & $5.7 \%$ \\
\hline Nodular goitre & 33 & $47.8 \%$ \\
\hline Colloid goitre & 08 & $11.5 \%$ \\
\hline Hashimoto's thyroiditis & 10 & $14.4 \%$ \\
\hline Follicular adenoma & 05 & $7.2 \%$ \\
\hline Follicular carcinoma & 02 & $2.8 \%$ \\
\hline Papillary carcinoma thyroid & 02 & $2.8 \%$ \\
\hline Anaplastic carcinoma & 02 & $2.8 \%$ \\
\hline Total & 69 & $100 \%$ \\
\hline
\end{tabular}

In the present study, there were 63 benign diagnosis and 6 cases of malignancy. Benign diagnosis (91.3\%) far outnumbered the malignant ones ( $8.6 \%$ cases).

Table 4: Cytology and histopathology correlation

\begin{tabular}{|l|c|c|c|c|}
\hline \multicolumn{1}{|c|}{ FNAC diagnosis } & No. of cases & Histopathology diagnosis & No. of cases & Remarks \\
\hline Colloid cyst & 3 & Colloid cyst & 3 & True negatives \\
& & & & \\
\hline Thyroglossal cyst & 4 & Thyroglossal cyst & 4 & True negatives \\
\hline Colloid goitre & 8 & Colloid goitre & 8 & True negatives \\
\hline \multirow{3}{*}{ Nodular goitre } & \multirow{3}{*}{34} & Nodular goitre & 33 & True negatives \\
\hline Hashimoto's thyroiditis & 10 & Follicular adenoma & 1 & False negatives \\
\hline Follicular neoplasm & 4 & Follicular Adenoma & 4 & True negatives \\
\hline \multirow{2}{*}{$\begin{array}{l}\text { Suspicious of } \\
\text { malignancy }\end{array}$} & \multirow{2}{*}{6} & Follicular carcinoma & 2 & True positives \\
\cline { 2 - 5 } & & Papillary carcinoma thyroid & 2 & True positives \\
\cline { 2 - 5 } & & Anaplastic carcinoma & 2 & True positives \\
\hline
\end{tabular}

Hence, after comparison of results of Cytology and Histopathology, FNAC showed overall diagnostic accuracy of $98.5 \%$ with specificity of $100 \%$, Sensitivity of $85.7 \%$, Positive predictive value of $100 \%$, and Negative predictive value of $98.4 \%$.

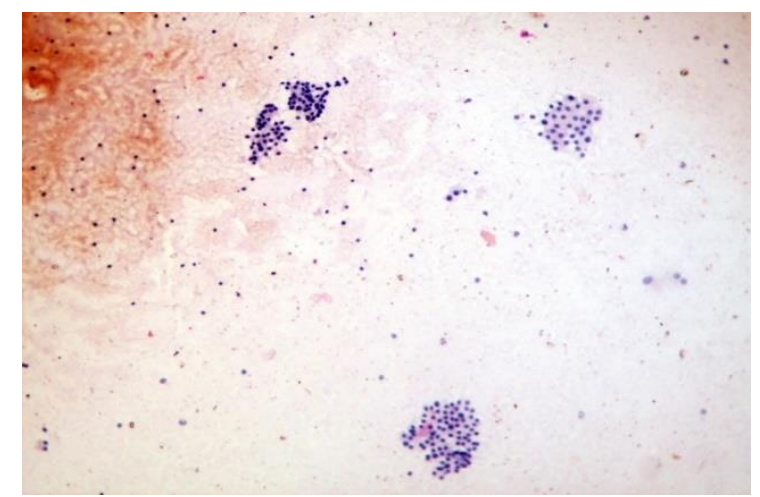

Fig. 1: FNA smear of nodular goitre showing macrofollicles and colloid. (Hematoxylin and eosin stain, 40X)

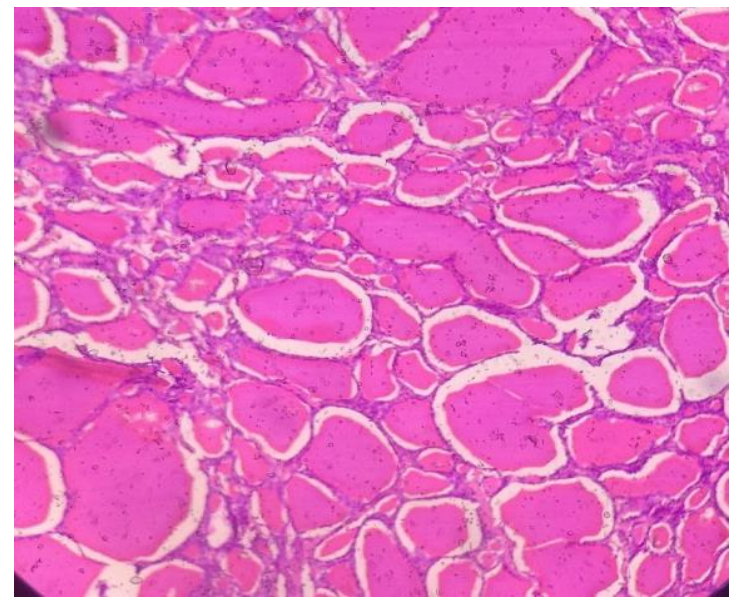

Fig. 2: Multinodular goitre on histopathology (Hematoxylin and eosin stain, 100X) 


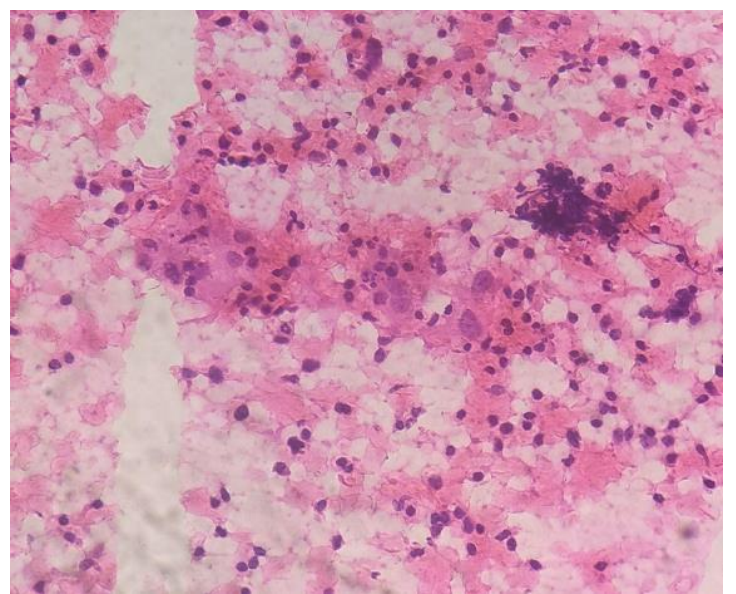

Fig. 3: FNA smear of Hashimoto's thyroiditis showing Hurthle cells. (Hematoxylin and eosin stain, 100X)

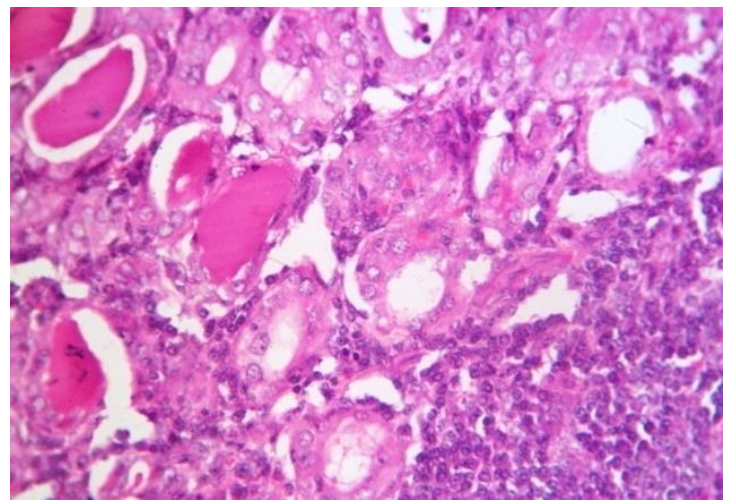

Fig. 4: Histopathology of Hashimoto's thyroiditis showing thyroid follicles with Hurthle cell metaplasia and lymphoid follicle (Hematoxylin and eosin stain, 100X)

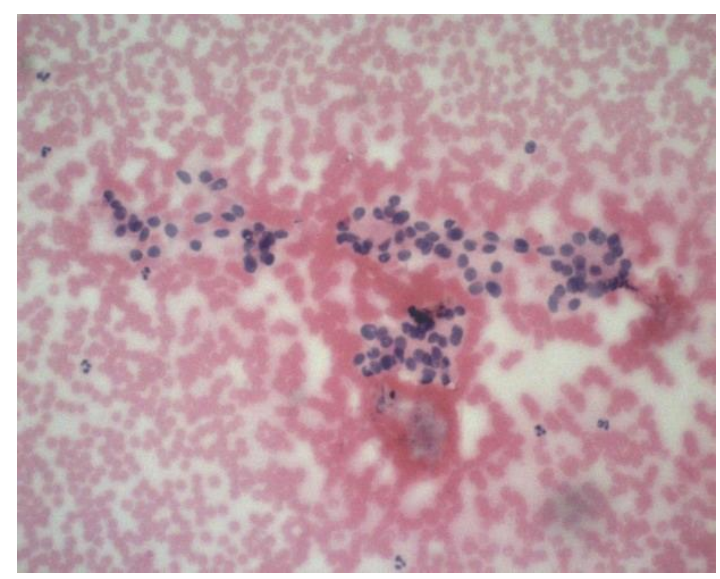

Fig. 5: FNA smear of Follicular neoplasm showing repetitive pattern of thyroid follicles (Hematoxylin and eosin stain, 40X)

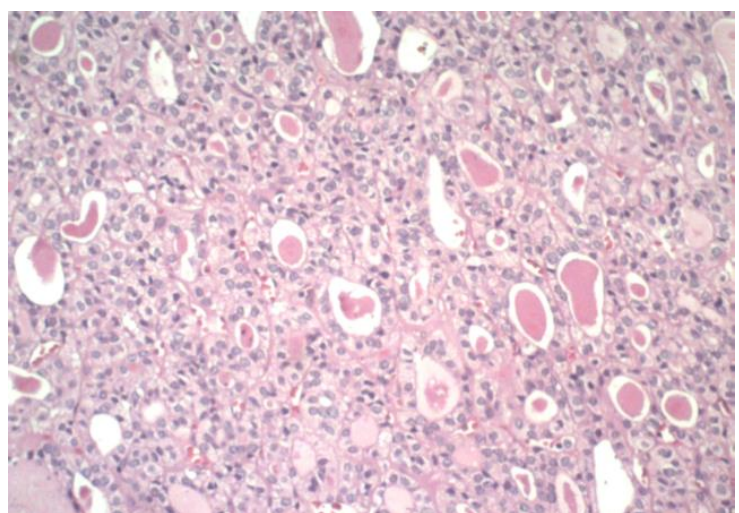

Fig. 6: Histopathology of Follicular adenoma (Hematoxylin and eosin stain, 40X)

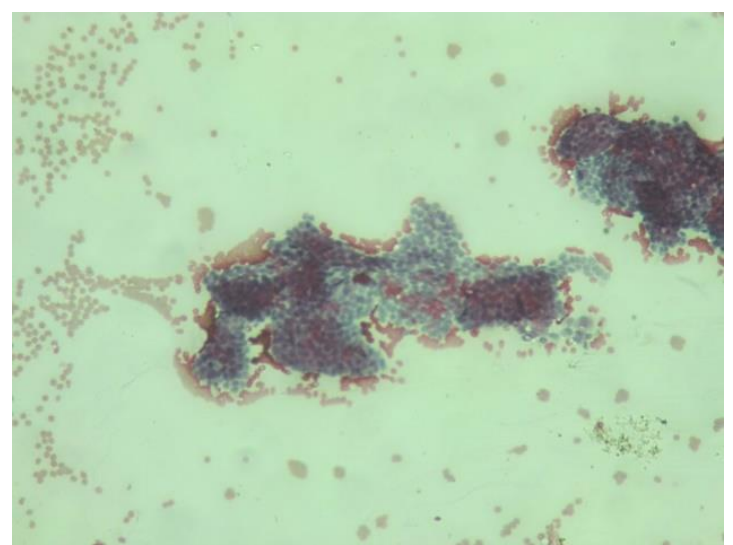

Fig. 7: FNA smear of Papillary carcinoma of thyroid with thyrocytes in papillaroid fragments (Hematoxylin and eosin stain, 40X)

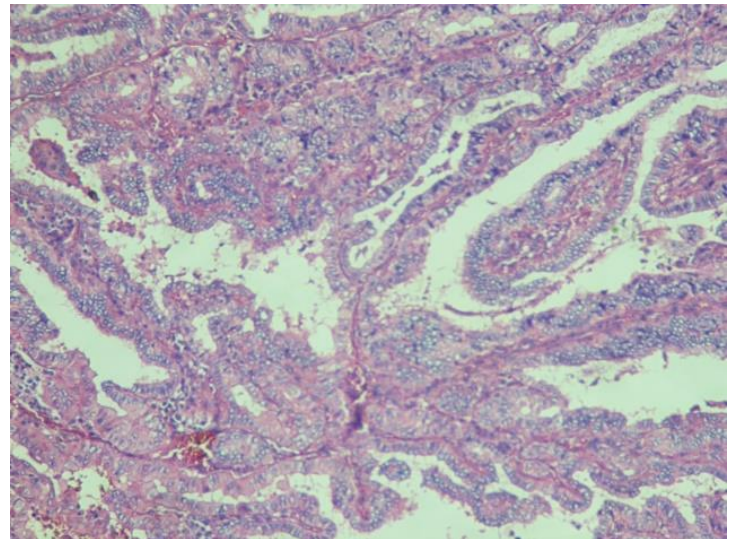

Fig. 8: Histopathology of Papillary carcinoma of thyroid showing branching papillary pattern with thyrocytes having optically clear nuclei. (Hematoxylin and eosin stain, 100X) 


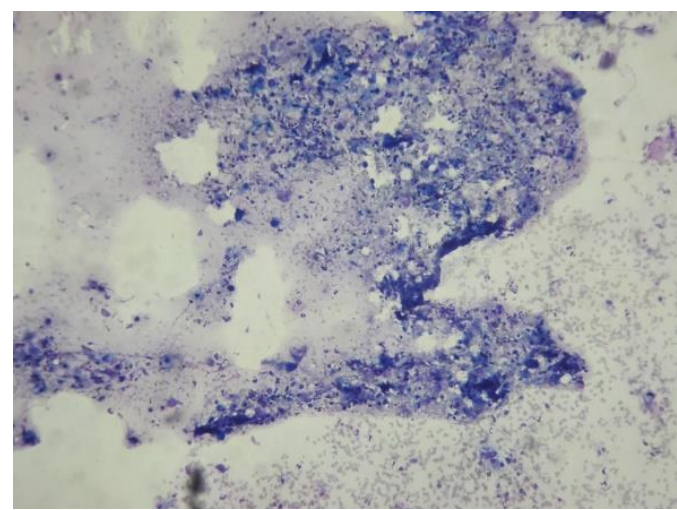

Fig. 9: FNA smear of anaplastic carcinoma of thyroid (Giemsa stain 40X)

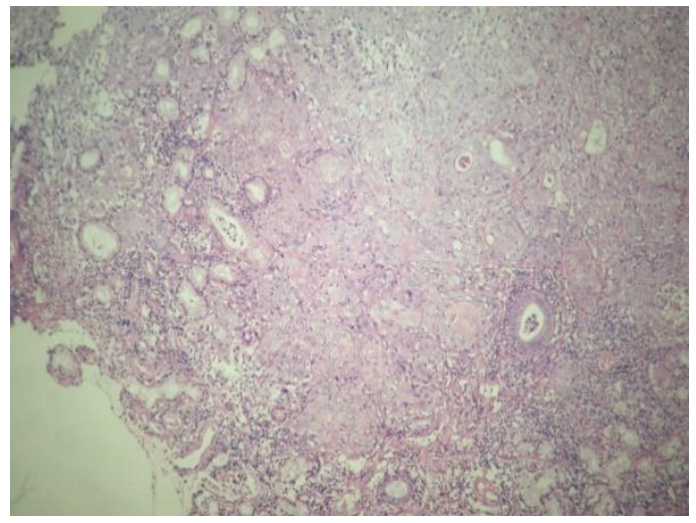

Fig. 10: Histopathology of Anaplastic carcinoma of thyroid with areas of squamous differentiation (Hematoxylin and eosin 40X)

\section{Discussion}

In the present study a total number of 94 cases were studied cytologically and comparison of cytology and histology was done in 69 cases. The patient age ranged from 9 years to 75 years. Majority of the patients were in the age group of 21-30 years followed by 31-40 years.

Aramani et $\mathrm{al}^{9}$ studied 60 patients with thyroid lesions and observed the age range from 15 to 65years with predominance of female patients. The male to female ratio was $1: 14$. Majority of the patients were in the age group of 21-40 years followed by 41-60years.

Agrawal et $a^{10}$ in their study of 281 patients with thyroid lesions observed the age range from 8 years to 76 years and a mean age of 38.24 years. Females were 227 and males were 54 with a male to female ratio of $1: 4.2$

In the study by Hathila et $\mathrm{al}^{11}$ the patient age ranged from 6 months to 80 years, with median of 43 years, and they too found a higher female preponderance with male to female ratio of 1:9. Our findings compare well with the observations of the above authors.

In the present study, most common clinical presentation was of solitary thyroid nodule that was seen in $45.7 \%$ cases followed by MNG and diffuse thyroid swelling in $12.7 \%$ and in $11.7 \%$ cases respectively. Tonape et $\mathrm{al}^{12}$ also observed STN in $42.8 \%$ cases in their study. MNG and diffuse goitre were seen in $17.1 \%$ and $25.7 \%$ cases respectively. Our findings compare well with the findings of these authors.

Table 5: Comparative studies on cytology

\begin{tabular}{|c|c|c|c|c|c|}
\hline Cytological diagnosis & $\begin{array}{c}\text { Present } \\
\text { study }\end{array}$ & $\begin{array}{c}\text { Balajiet } \\
\text { al }^{13}\end{array}$ & $\begin{array}{c}\text { Ramteke et } \\
\mathbf{a l}^{14}\end{array}$ & $\begin{array}{c}\text { Agrawal et } \\
\text { al }^{10}\end{array}$ & $\begin{array}{l}\text { Chaudhari, } \\
{\text { et } \text { al }^{15}}^{\text {, }}\end{array}$ \\
\hline Colloid cyst & 03 & - & 24 & & 24 \\
\hline Colloid goitre & 11 & 423 & 229 & 84 & \\
\hline Nodular goitre & 41 & 26 & - & 09 & 62 \\
\hline Hashimoto's thyroiditis & 26 & - & 07 & 14 & 25 \\
\hline Lymphocytic thyroiditis & 02 & - & 47 & - & - \\
\hline Subacute thyroiditis & 01 & - & 08 & 02 & - \\
\hline Acute thyroiditis & - & -- & 05 & - & - \\
\hline MNG with cystic change & - & 167 & - & - & - \\
\hline Thyroglossal cyst & 04 & - & - & 02 & - \\
\hline Follicular neoplasm & 04 & 16 & 58 & 07 & 14 \\
\hline Hurthle cell neoplasm & - & 01 & 01 & 04 & 04 \\
\hline Malignancy & 02 & 05 & - & 05 & - \\
\hline PTC & - & 20 & 04 & 01 & 06 \\
\hline Medullary & - & 6 & & 01 & - \\
\hline Anaplastic & - & 02 & 03 & 02 & 01 \\
\hline Inadequate sampling & & 05 & & & \\
\hline Total & 94 & 659 & 320 & 134 & 136 \\
\hline
\end{tabular}

In the present study, benign lesions were more common than malignant ones and on cytology most commonly reported entity was of nodular goitre and Hashimoto's thyroiditis. Other authors as above have 
also reported more of non-neoplastic/ benign conditions.

In our study, on histopathology, benign thyroid lesions were more common at $91.3 \%$ and malignant lesions were $8.6 \%$ which is comparable with the findings of Kantasueb et al. ${ }^{16}$

Table 6: Comparative studies for sensitivity and specificity

\begin{tabular}{|l|c|c|c|c|}
\hline \multicolumn{1}{|c|}{ Studies } & Year of study & Sensitivity & Specificity & Accuracy \\
\hline Aramani et al $^{[9]}$ & 2015 & $96.3 \%$ & $100 \%$ & $96.6 \%$ \\
\hline Pandey et al $^{[17]}$ & 2012 & $57.1 \%$ & $90 \%$ & $80.2 \%$ \\
\hline Gupta et al $^{[18]}$ & 2010 & $80 \%$ & $86 \%$ & $84 \%$ \\
\hline Hathila et al $^{[11]}$ & 2016 & $87.5 \%$ & $96.1 \%$ & $95 \%$ \\
\hline Present study & 2018 & $85.7 \%$ & $100 \%$ & $98.5 \%$ \\
\hline
\end{tabular}

\section{Conclusion}

FNAC technique showed good reliability in diagnosing thyroid lesions in our institute. It showed $100 \%$ specificity, high sensitivity and high accuracy. Though FNAC cannot replace the gold standard of histopathology, this technique has many advantages and helps in preoperative diagnosis of thyroid lesions which guides the further clinical management of thyroid swellings.

\section{References}

1. Tabaqchali MA, Hanson JM, Johnson SJ, Wadehra V, Lennard TW, Proud G. Thyroid aspiration cytology in Newcastle: A six year cytology/ histology correlation study. Ann R Coll Surg Engl. 2000;82:149-55.

2. Cooper DS, Doherty GM, Haugen BR, Kloos RT, Lee SL. American Thyroid Association (ATA) Guidelines Taskforce on Thyroid Nodules and Differentiated Thyroid Cancer. Revised American Thyroid Association management guidelines for patients with thyroid nodules and differentiated thyroid cancer. Thyroid. 2009;19:1167214.

3. Ridgway EC. Clinical review 30: Clinician's evaluation of a solitary thyroid nodule. J Clin Endocrinol Metab. 1992;74:231-5.

4. Orell SR, Sterrett GF, Whitaker D. Thyroid in Fine needle aspiration cytology, $4^{\text {th }}$ ed, Philadelphia: Churchill Livingstone;2005:125-164.

5. Asotra S, Sharma J. Role of AgNORs in thyroid lesions on FNAC smears. J Cytol. 2008;25:18-22.

6. Layfield LJ, Cibas ES, Gharib H, Mandel SJ. Thyroid aspiration cytology: Current status. CA Cancer J Clin. 2009;59:99-110.

7. Polyzos SA, Kita M, Avramidis A. Thyroid nodules stepwise diagnosis and management. Hormones (Athens). 2007;6:101-9.

8. Shere SK, Kulkarni AS, Phulgirkar PP, Anjum S, Patil SP, Bindu R. Correlation of fine needle aspiration cytology with histopathology in diagnosis of thyroid lesions. J Evolution Med Dent Sci. 2013;2(26):4826-31.

9. Aramani SS, Gururajaprasad C. A cytohistopathological correlation of thyroid lesions with critical evaluation of discordant cases: an experience at a tertiary care hospital. www.pacificejournals.com/apalm

10. Agarwal R, Saxena M, Kumar P. A study of fine needle aspiration of thyroid lesions with histopathological correlation. Indian Journal of Pathology and Oncology. 2015;2(4):277-283.

11. Hathila R, Patel S, Vaghela P, Makwana G, Parmar P. Cytology findings of the thyroid lesions with the histopathology findings correlation. Int J Med Sci Public Health. 2016;5:642-646.

12. Tonape T, Athavale VS, Shetty I, Lad A, Batra G, Rege I. Clinico-Pathological Correlation of Thyroid Swellings. Journal of Medical Science and Clinical Research. 2016;4(12):14382-85.

13. Balaji S, Kumbalingam B, Muthukrishnan SSK, Karuppanan U. Fine needle aspiration cytology and histopathological correlation of nodular lesions of thyroid: a study. J Evolution Med Dent Sci. 2016;5(52):2278-4748.

14. Ramteke DJ, Mulay PS. Cyto-histopathological correlation of thyroid lesions. Int J Res Med Sci. 2017;5(4):1425-1429.

15. Chaudhari S, Hatwal D, Bhat P, Batra N, Bhat $S$. Cytological Evaluation of Thyroid Lesions and its Correlation with Histopathology: A Prospective Study. International Journal of Scientific Study. 2015;3(8).

16. Kantasueb S, Sukpan K, Mahanupab P. The study of thyroid lesions and the correlation between histopathological and cytological findings at Maharaj Nakorn Chiang Mai Hospital between 2003 and 2007. Chiang Mai Med J. 2010;49:105-10.

17. Pandey P, Dixit A, Mahajan NC. Fine needle aspiration of the thyroid: A cytohistologic correlation with critical evaluation of discordant cases. Thyroid Research and Practice. 2012;9(2):32-39.

18. Gupta M, Gupta S, Gupta VB. Correlation of Fine Needle Aspiration Cytology with Histopathology in Diagnosis of Solitary Thyroid Nodule. Journal of Thyroid Research. Volume 2010; Article ID 379051, 5 Pages.

How to cite this article: Kanyakumari M, Pushpalatha K. Cytological evaluation of thyroid lesions and its correlation with histopathology in a teaching hospital. Indian $\mathbf{J}$ Pathol Oncol. 2018;5(4):625-630. 